\title{
Adornos Contemporâneos: seus significados no âmbito da joia, bijuteria e ornamento corporal
}

Adornments Contemporaries : their meanings under jewel, bijouterie and body ornaments

\section{Silvia Carla Sarti Rocha}

\section{Maria Antonia Benutti}

Professora Doutora, Coordenadora do Curso de Artes Visuais, Unesp Faac, Bauru mariabenutti@gmail.com

\section{Marizilda dos Santos Menezes}




\section{Adornos Contemporâneos: seus significados no âmbito da joia, bijuteria e ornamento corporal}

Adornments Contemporaries : their meanings under jewel, bijouterie and body

ornaments

Silvia Carla Sarti Rocha, Maria Antonia Benutti e Marizilda dos Santos Menezes

\section{Resumo}

Este artigo, tendo por referência o Brasil, explora algumas significações relacionadas ao século XX e aos adornos, sejam eles, joias, bijuterias ou ornamentos corporais. Determinou-se como ponto de partida as transformações tecnológicas geradas pelas mudanças político-econômicas. A modernização industrial na década de 1950 trouxe renovação cultural, o que possibilitou novos hábitos e costumes que frutificaram sob vertentes de vanguarda no contexto contemporâneo brasileiro. O uso adequado e mais arrojado de matéria-prima e a relação entre custo e benefício se mostraram viáveis e impulsionaram a economia mundial. Por meio de pesquisa de campo e análise bibliográfica, constatou-se que joia, bijuteria e ornamento corporal, tiveram suas fronteiras aproximadas no âmbito do contemporâneo. A intersecção de diferentes abordagens com análises de alguns pontos no escopo do design conduziram esse estudo.

Palavras- chave: joia, bijuteria, adorno e design

\begin{abstract}
This article, by reference to Brazil, aims to explore some meanings related to the twentieth century and adornments whether jewelry, costume jewelry and body ornaments. It was determined as a starting point the technological transformations generated by political and economic changes. The industrial modernization in the 1950s brought cultural renewal which allowed new habits and customs that bore fruit in the forefront strands of contemporary Brazilian context. Adequate and bolder use of raw materials and the relationship between cost and benefit proved viable and boosted the world economy. Through field research and literature review, it was found that jewelry, bijouterie and corporal ornament had their boundaries approximated in the contemporary scope. The intersection of different approaches to analysis of some points in the design scope led the study.
\end{abstract}

Keywords: jewelry, costume jewelry, ornaments and design. 


\section{Introdução}

(...) o homem pré-histórico percebia a beleza nas coisas que o cercavam, espírito e matéria se uniam numa relação mítico-mágica, onde o resultado ficava plasmado nos objetos que fabricava (BISOGNIN, 2012, p. 57-7).

Adornos sempre foram objetos atrativos para a humanidade. Considerando lugares primitivos ou inseridos no cotidiano das cidades é quase impossível encontrar pessoas sem um acessório. $\mathrm{O}$ ato de adornar atende a uma necessidade humana relacionada a três aspectos: estético ligado à forma; simbólico, ao significado emocional; prático à função. $\mathrm{E}$ é nessa tríade que encontramos o design. Considerado ferramenta de gerenciamento de conhecimentos, teve e tem papel significativo quando falamos sobre esses ornatos. Heskett $(2008$, p.13) aponta que, para traduzir a vida e atender às necessidades do homem, o design dá forma ao meio por um caminho diferente do encontrado na natureza.

Por outro lado, esses objetos estão profundamente integrados na história da indumentária por sua relevância econômica. Geralmente envolvem o fazer manual. Movimentam de forma considerável a indústria da moda pela fomentação de atividades variadas com retorno financeiro significativo, conforme mencionam Medina (2009, p. 5) e Barroso (2013). Danielle Allérès (2006) destaca que civilizações suficientemente desenvolvidas do ponto de vista técnico ou científico concederam papel importante às artes e aos refinamentos, com nível de consumo elevado e requintado, no que se refere à apresentação pessoal. Isso comprova a importância dos adornos no resgate histórico das sociedades. Ponderar sobre alguns fatos que se relacionam a esses ornatos merece apreço diante de mais de sete mil anos de joalheria mundial - e também da peculiar história desse ofício no Brasil. O conhecimento circula e muda com fluidez frenética. É comum as pessoas permanecerem na superfície dos conteúdos como tentativa de estar atualizado. Informações de variadas fontes fazem o diferencial, porém a cautela se faz necessária diante de tantas ideias.

É importante avaliar que conclusões apressadas podem gerar percepções equivocadas. Outra realidade a ser considerada é não termos ainda um curso superior de joalheria nem uma normatização oficial.

Esses fatos talvez sejam demarcadores importantes que nos mantém limitados e desorganizados. A falta de referência confiável e reconhecida pode causar perdas 
muitas vezes incalculáveis em termos de patrimônio cultural. Nesse sentido, muitas técnicas e mestres artesões estão se perdendo. Os contínuos avanços tecnológicos alteram a forma como produtos são fabricados, comercializados e usados na sociedade, porém isso não justifica o abandono da preservação de um passado histórico. Como agir diante da escassez de literatura e pesquisa científica que vigora no país? No Brasil, a conjunção de qualidades como criatividade, vocação para o artesanal e a diversidade de materiais deveria fazer parte das iniciativas de forma mais incisiva. E se esse conjunto estivesse associado a investimentos em educação, a pesquisa e a uma economia criativa poderia gerar possibilidades interessantes de desenvolvimento com bases seguras e inovadoras.
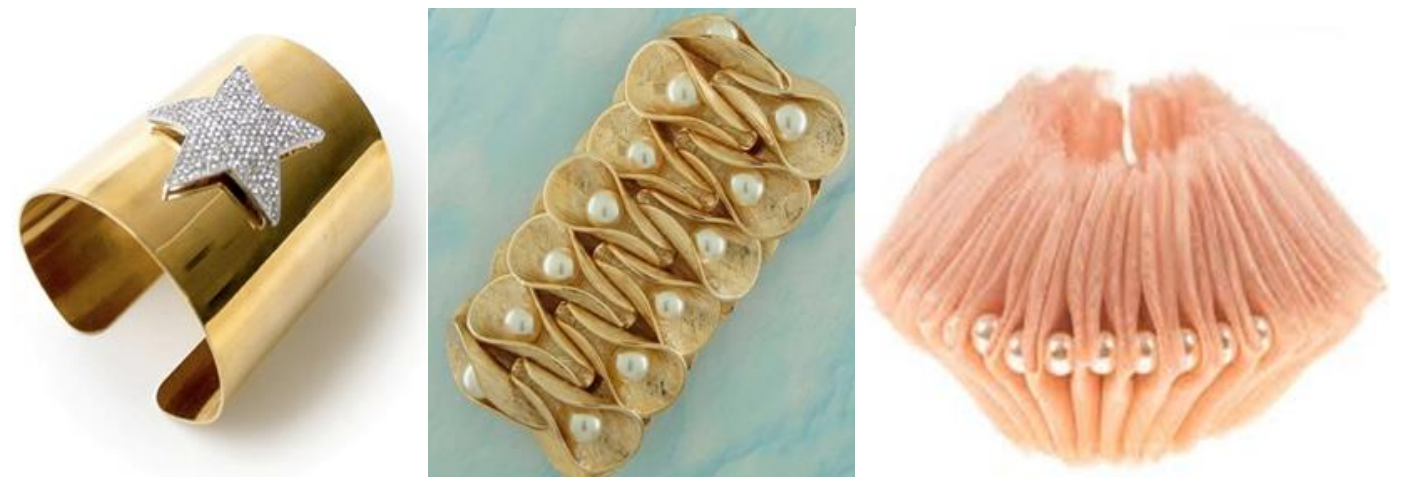

Figura 1 - Joia, bracelete Mulher Maravilha, Joalheria Noir e DC Comics. Fonte: athas.com.br. Figura 2 - Bijuteria, bracelete Conchas, Ibija Bijuterias. Fonte: www.ibijabijuteria.com.br. Figura 3 - Adorno, bracelete. Fonte: www.infojoias.com.br.

Portanto, estabelecer um entendimento bem pautado e atualizado sobre adornos, que aborde as diferenças entre joia, bijuteria e ornamento corporal, Figuras 1, 2 e 3 respectivamente, pode contribuir para o planejamento de ações que conduzam a um melhor tratamento para essa parte de nossa cultura. Uma economia que estabelece alternativas diferenciadas possibilita a construção de vantagens comerciais tanto no mercado local como no globalizado. Compreender as fronteiras entre esses adornos dentro de um contexto contemporâneo, considerar parâmetros relacionados aos materiais utilizados, e adentrar a rota dos métodos de produção com abordagem voltada para a ótica do design podem ser alguns dos caminhos para a análise que se propõe. 


\section{Sob a perpectiva etimológica}

Dentro do conceito tradicional, adornos se referem ao que serve para enfeitar e embelezar. Podem ser denominados como atavios, enfeites, artefatos, ornamentos ou adereços. Nesses critérios enquadram-se as joias, bijuterias, ornamentos corporais. Em alguns casos esses objetos são até considerados instalações. Assim, numa visão conservadora:

Joia vem do francês joie, joiel ou do latim jocalis. Pode ser compreendida como objeto de adorno pessoal, feito com material precioso (ouro, prata, pedras preciosas); estar ligada a brincadeiras; representar artefato de valor artístico; e também a quantia que se paga para admissão em associações ou grêmios. Pode ainda significar pessoa ou coisa de grande estima.

Bijuteria também vem do francês bijouterie. Está relacionada a quinquilharia ou ao uso de algo para enfeitar o corpo ou a roupa. Porém, num primeiro momento, foi definida como ornamento de certo valor. É própria para adereços como broches, brincos e anéis de imitação feitos de ligas de metais não nobres que imitam ouro ou prata, com ou sem pedras naturais e artificiais, entre outros materiais. É ainda considerada ramo da ourivesaria.

Adorno corporal pode ser percebido como tudo que embeleza o corpo. Nesse caso incluem-se peças fabricadas com materiais diversos, artefatos luminosos, tatuagens, pinturas corporais e outros objetos peculiares como penas, ossos, conchas, escamas, insetos e animais. Há alguns arranjos que são tão surpreendentes que melhor seria nomeá-los instalações ${ }^{1}$ (Figuras 4, 5 e 6).

Tendo por base Bisognin (2012, p.57-70) e Gola (2008, p. 24-40) mais tarde o desenvolvimento da agricultura de cereais e da criação de animais favoreceu a formação de associações humanas maiores e mais desenvolvidas. Os caçadores nômades deram espaço para as primeiras tribos sedentárias agrupadas em colônias ou povoados e estas para as civilizações egípcias e europeias mais adiante.

\footnotetext{
${ }^{1}$ Instalação pode ser compreendida como algo colocado em algum espaço ou lugar. É uma linguagem da Arte Contemporânea que promove o diálogo entre a obra, o espaço e o espectador.
} 

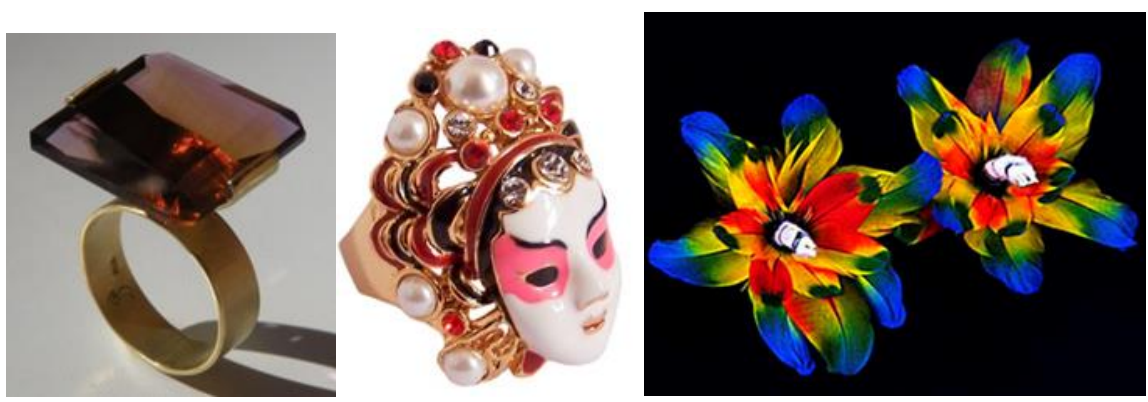

Figura 4 - Joia, anel Desejo de Mãe, Sagrado Profano. Foto Paulo Rocha.

Figura 5 - Bijuteria, anel Máscara, Anjinha da Moda. Fonte: www.anjinhadamoda.com.br.

Figura 6 - Adorno indígena para orelha. Fonte: imagemdobrasil.art.br.

O intercâmbio cultural ocorrido pela troca de saberes e vivências tornou os adereços comuns em todos os grupos étnicos. Neste contexto o colar foi o mais usual na ornamentação precedido somente pela pintura corporal. Os adornos foram aperfeiçoados no transcorrer das épocas tanto estética quanto tecnicamente. A partir das peças primitivas caminhamos para formas mais complexas, entre elas anéis e braceletes, finamente montadas. Nesse decurso incluem-se as peças em cerâmica ou polidas.

Através dos acervos encontrados em museus compreende-se que objetos naturais fascinavam os povos ancestrais por sua raridade, brilho e beleza e a busca por materiais inusitados tornou-se uma constante, fazia parte de um cotidiano. Junto com ossos e lignita, se lavrava ardósia, esteatita, alabastro, quartzo, ametista, jadeíta, nefrite, diorito, callais (mineral semelhante a turquesa), vidro, o cobre e ouro. O material que se utilizava diferia de região para região, de acordo com as existências naturais e os progressos de intercâmbio.

A Idade da Pedra Lascada foi seguida pela dos Metais com o domínio do fogo e da escrita. E é nesse momento que podemos relacionar o surgimento das primeiras joias considerando apenas o emprego de metal nobre, ou seja, não avaliando o grau de complexidade e elaboração das peças. O avanço técnico foi expressivo na produção de artefatos ao usar moldes de pedra ou barro para colocar o cobre ou ouro derretidos bem como o martelo para forjar os objetos depois de frios. Essa técnica de fundição primitiva se tornou adiante base referencial para a técnica industrial (GIORDANI, 1993).

Gola (2008, p. 24-40) aponta que o ouro desde as épocas mais remotas foi considerado metal nobre. $\mathrm{O}$ fato de não oxidar, fundir-se a si mesmo e ser extremamente dúctil agregou à sua funcionalidade um alto valor ornamental. Por ser facilmente retirado da natureza, pelo seu brilho, sua beleza e cor, provavelmente foi associado como 
dádiva dos deuses e relacionado ao sol. A autora menciona que joia de ouro ou prata com pedras de cor começaram a surgir no início da Idade do Bronze. A partir daí houve um desenvolvimento contínuo de diversas técnicas e desenhos. Desse modo, considera que o conceito de joia pode ser extremamente amplo. Apesar da variedade das formas e materiais, a joalheria moderna iniciou-se após a Segunda Grande Guerra.

Surgiram novos materiais e novas técnicas, associadas às inusitadas propostas com ordenamento de cores diferenciado e arrojado. A joalheria passou a ser verdadeiramente uma arte como nas Figuras 7 e 8 . Há milênios como símbolos de luxo, amuletos de proteção ou com intuito de se diferenciar ao enfatizar beleza e poder, as joias conservaram sua importância. Conquistaram seu espaço na história como acervo ao transformar-se em patrimônio cultural. Segundo levantamentos divulgados pelo Serviço Brasileiro de apoio às Micro e Pequena Empresas - (SEBRAE, 2010) num sentido mais amplo no século XVII a bijuteria, joia de fantasia, surgiu na Europa como réplica de joias e era comprada por uma faixa da sociedade com poder econômico limitado para adquirir peças de ouro.

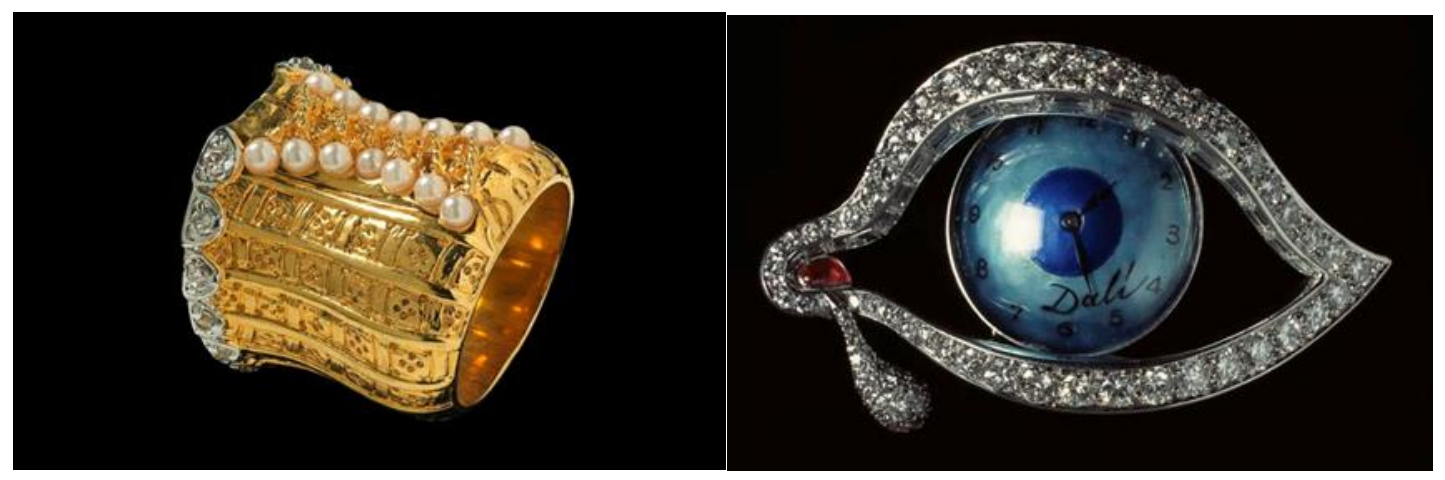

Figura 7. Joias Salvador Dali. Fonte: shop.salvador-dali.org.

Figura 8. Joias Salvador Dali. Fonte: alistadlucas.wordpress.com.

Dados divulgados em 2014, por entidades como Associação Joalheira Americana de Fabricantes e Fornecedores e Sindicato dos Trabalhadores da Indústria Joalheira de São Paulo (MJSA/Sintra), mencionam que nessa época as pastas altamente reflexivas, o vidro e as ligas de cobre e zinco eram alternativas para simular a joia de ouro. Seu uso relacionou-se ainda ao contexto religioso por meio de amuletos para proteção pessoal, é o caso das medalhas, escapulários, cruzes, pulseiras com imagens de santos e pencas. No pós-guerra a busca por materiais novos e mais baratos aumentou a demanda no 
mercado forma sólida.

A joia de fantasia conquistou de forma definitiva outro aporte, deixou o perfil de imitação pelo desenvolvimento de uma linguagem estética genuína e bem mais autêntica. Aqui, o design teve papel importante. Assim a bijuteria espalhou-se sem distinção social nem econômica. Diferentes propostas, feitas com materiais menos nobres, tornaram-se comuns nas sociedades antigas chegando até as atuais. A fase dourada desse acessório foi entre 1930 e 1950, fruto do trabalho de talentosos designers que ousaram com materiais inesperados e técnicas inovadoras. No ano de 1951 a revista Vogue Americana concedeu para a indústria de bijuteria ${ }^{2}$ o selo da alta moda. Nas Figuras 9, 10 e 11 as peças requintadas e contemporâneas.

Ainda com base nos dados do SEBRAE (2010) e MJSA/Sintra (2014), em Paris nos anos 1920, com réplicas glamorizadas, a visionária Coco Channel tornou-se pioneira ao tirar das bijuterias o estigma de meras imitações de joias. Foi o começo da bijuteria moderna, o termo joia de fantasia ou bijuteria tornou-se popular.
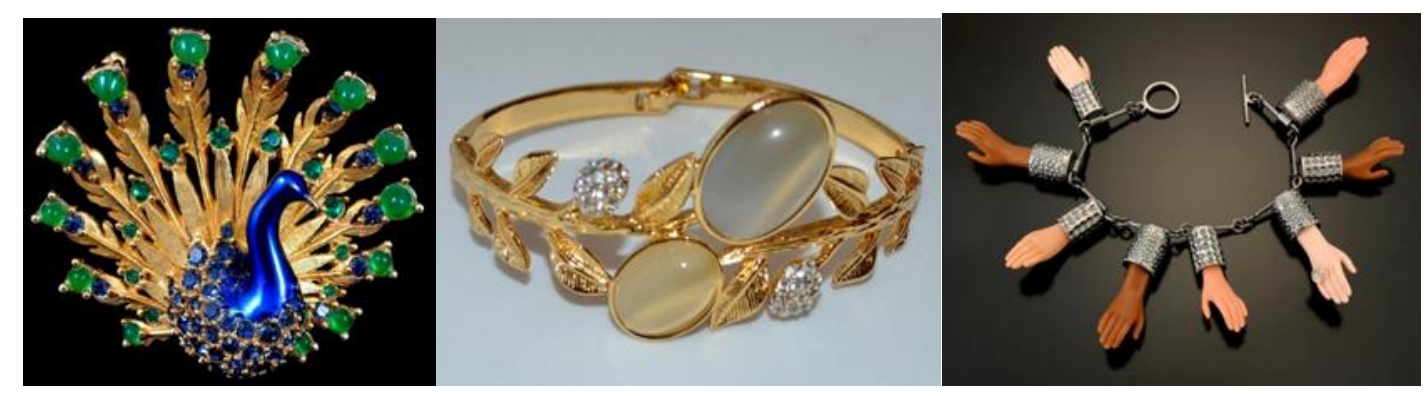

Figura 9 - Bijuteria sofisticada, Marcelo Boucher. Fonte: www.egort.comunidades.net. Figura 10 - Bijuteria classica, Corrente de Ouro. Bijuterias. Fonte: correntedeouro.net. Figura 11 - Bijuterias lúdicas, Margaux Lauge. Fonte: design-milk.com.

Pautados nos dados da MJSA/Sintra (2014) na Segunda Guerra, com o desaparecimento das matérias básicas, a maioria das peças era produzida com prata e banhada em ouro ou ródio, simulando a aparência da platina. Porém a prata era cara para a situação econômica daquele momento. Para manter o mercado estável as indústrias investiram em projetos arrojados com materiais mais baratos como madeira, plástico, cerâmica, e tecido que possibilitaram propostas bem atraentes e diferenciadas em termos de estética.

\footnotetext{
${ }^{2}$ Segundo Pompei (2013), bijuterias levam em seu corpo diferentes metais que não são considerados nobres, é apenas a superfície que recebe uma fina camada de metal nobre ou ligas especiais que proporcionam um certo brilho e acabamento mais refinado, sendo sua durabilidade limitada.
} 
Nos anos 60, com Paco Rabanne, aconteceu outro momento de relevância para a bijuteria. Rabanne iniciou sua carreira com a produção diferenciada desses complementos para famosas casas francesas de alta costura, conhecidas como maisons. Inovou quando criou peças com personalidade sem o objetivo de imitar a joalheria tradicional.

A bijuteria é um acessório básico usado corriqueiramente por pessoas de todas as idades e estilos. Renova-se constantemente sem o compromisso de durar longos períodos. E mais que isso, bijuterias com personalidade e design moderno continuam a conquistar um público cada vez maior por sua originalidade e preço. No que se refere a produção de bijuterias(folheadas ou chapeadas) ${ }^{3}$ é pertinente mencionar que o Brasil é detentor de três grandes pólos: Limeira-São Paulo, Guaporé-Rio Grande do Sul e CaririCeará. No escopo dos ornamentos corporais o entendimento surgia geralmente de algo oriundo dos costumes pertinentes aos índios (Figura 11), a povos africanos ou rudimentares. Porém, da mesma forma que joias e bijuterias, esses adornos corporais estabeleciam significados complexos traduzindo a identidade cultural desses povos. Os aparatos indígenas ou africanos possuem riqueza visual e função simbólica e honorífica da mesma forma que cetros e coroas para a cultura ocidental. A arte plumária, forma de comunicação e linguagem, é uma das expressões plásticas mais impactantes das culturas originárias do Brasil. Segundo o antropólogo e escritor Darcy Ribeiro (2010, p.51): “é na plumária que observamos a atividade mais eminentemente artística dos nossos índios".

Baseados nas pesquisas de Lody (2011) pode-se destacar as coloridas e trabalhadas contas e pencas, adornos referenciais da cultura afrobrasileira patrimônio ímpar dos mestres africanos aqui estabelecidos. Tanto as contas como plumagem foram usadas como fontes de inspiração para muitos designers joalheiros e de moda. Por outro lado, e com base no que já foi argumentado o surgimento de novas necessidades geradas pelas guerras mundiais e pelas mudanças político-econômicas e de costumes, associados aos avanços diversos e à difusão dos conceitos em design no começo do século $\mathrm{XX}$, corroboraram a criação de um adereço que não era nem bijuteria nem joia, mas trazia

\footnotetext{
${ }^{3}$ Folheados são artefatos fabricados geralmente por fundição com metal ou liga não nobre e têm em seu acabamento banho de outros metais como ouro, prata, ródio, titânio. Chapeados são artefatos fabricados em chapas de metal não nobre que recebem uma microlâmina de metal nobre para então serem trabalhadas.
} 
uma concepção original pela manipulação diferenciada dos materiais (Figuras 12,13 e 14), pela proposta conceitual ligada ao design, pela forma atípica de uso, chegando a gerar uma interatividade com seu usuário, ou pelo posicionamento singular no corpo.

Diferente da referência inicial destinada aos ornamentos corporais, esses podem ser inseridos na mesma denominação, só que agora com ressignificação relacionada ao inovador e não mais ao histórico rudimentar ou primitivo do passado. Com o avanço industrial e digital, e pela introdução do design no país, as concepções desses ornatos se modificaram com a evolução dos tempos.

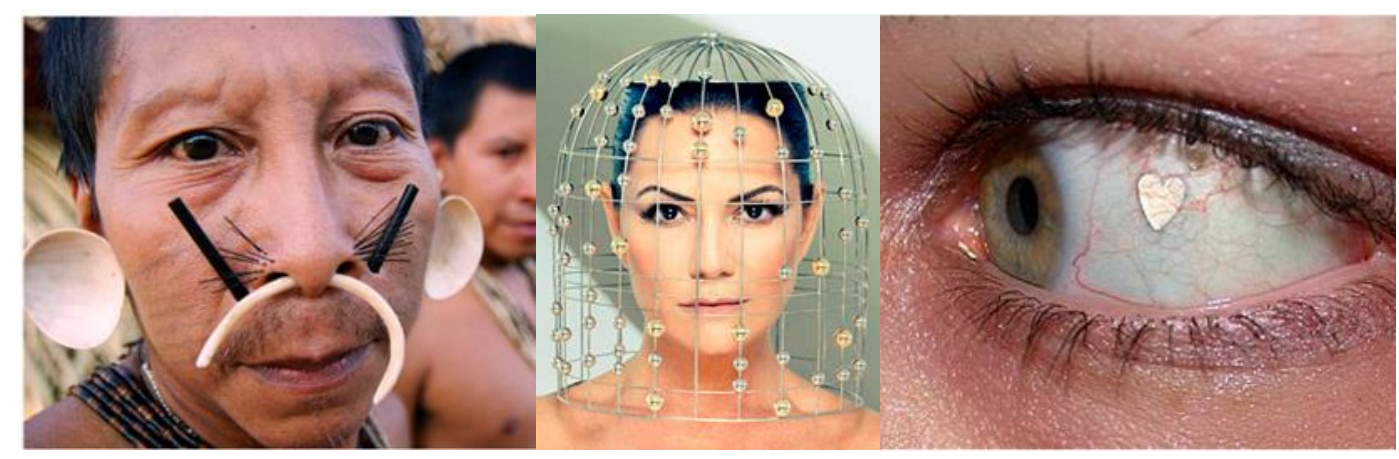

Figura 12 - Índio matis, ornamentos de corpo, Amazônia. Foto Alex Almeida/Folha imagem/ www.scielo.br. Figura 13 - Adorno contemporâneo Big Bang. Fonte: Anglo Gold Ashant/ www.midiorama.com.br

Figura 14 - Ornamento de ocular. Fonte: www.big1news.com.br.

\section{No âmbito da joalheria brasileira}

O Brasil até a metade do século XX conformava-se em ser o país do futuro. Com o fim da segunda Guerra, a política mundial de reconstrução estimula o consumo em todas as esferas sociais. Vivenciamos as glórias dos "anos dourados". Segundo Niemeyer $(2014$, p.35-46, 69) a conjunção de criatividade e de inovação se manifestou na música com a Bossa Nova; na literatura pelas obras de Guimarães Rosa; na pintura com Tarsila do Amaral e Di Cavalcanti; no paisagismo temos Burle Max e na joalheria com joias, esculturas, objetos e ferramentas diferenciadas de Caio Mourão, Reny Golcman, Ulla Jonshen, Ricardo Mattar, Renée Sasson e Salvador Francisco Neto.

Avanços científicos e tecnológicos significativos aconteceram a partir dos anos 1960-1970. Sob a égide do progresso, a consolidação do design no Brasil se fez pela criação de cursos no Instituto de Arte Contemporânea (IAC) em São Paulo e na Escola Superior de Desenho Industrial no Rio de Janeiro. Para Niemeyer (2014, p. 35-46, 69) o design nessa fase ligava-se diretamente à adequação do processo produtivo 
industrializado. Consumo voraz e comunicação massificada geraram rupturas com a tradição, com surgimento de um movimento político-cultural de carácter libertário, a contracultura. Em 1980 conhecemos o mundo digital através de programas de design, o computador tornou-se equipamento "mor" para o desenvolvimento de projetos e produtos. A comunicação continuou mais veloz e nossa noção de tempo mudou. Esse cenário conduz o país num período de trinta anos para posição de destaque.

Rocha $(2014$, p. 39-50, 120) ressalta que a partir dos anos mil novecentos e noventa recebemos avaliações positivas por parte da comunidade internacional e na virada do século fomos considerados nação emergente. A autora lembra, ainda, que no transcorrer dos eventos a joalheria também sofreu mudanças. Os conhecimentos que antes eram transmitidos como herança pela prática direta para as gerações futuras se extinguiram. O progressivo êxodo rural por melhores oportunidades nas cidades propiciou a criação de escolas profissionalizantes para atender à demanda gerada pela indústria. Surge um ensino fragmentado destinado a formar técnicos, profissionais treinados para suprir uma necessidade específica do setor. Esses aprendizes saíam capacitados a realizar apenas algumas partes das técnicas de ourivesaria.

Esse avanço trouxe facilidades, porém a joalheria perdeu em termos de qualidade. A capacidade de criar estratégias de futuro e planejamentos consistentes para viabilizar produtos complexos, de valor real para a comunidade, só é viável dentro da visão do projeto como um todo. O conhecimento cultural parcial levou ao esquecimento de artistas, artesões e mestres joalheiros e à perda de técnicas importantes. A geração e implantação de iniciativas que promovessem uma melhoria na boa educação e a criação de mecanismos que valorizem e preservassem o patrimônio cultural começaram a fazer parte das metas governamentais de forma contínua.

\section{Aproximação dos conceitos no contexto contemporâneo}

Como consequência natural da evolução tecnológica as diferenças entre os adornos ficaram mais difíceis de serem identificadas pelo consumidor. Houve a aproximação das fronteiras que diferenciavam joias, bijuterias e ornamentos corporais (Figuras 15, 16 e 14). O fato de não termos um rico e diversificado registro da história do artesanal ou da joalheria brasileira, associado à ausência da normatização oficial, propicia uma situação confusa. Dentro dessa percepção equivocada temos, por exemplo, a insistência no uso do termo semiprecioso. Essa prática ainda é difundida pelo 
comércio nas cidades menores ou mais interioranas como tentativa de imprimir valor a objeto feito com materiais menos nobres.

Outra situação da mesma forma capciosa e que é fruto de um marketing mais agressivo que não traduz a realidade é compreender que realmente diamantes são eternos, mas as outras gemas são também. O valor está vinculado ao sistema de extração dos minerais e à raridade com que as pedras são encontradas na natureza, além de qualidades como cor, dureza, transparência e lapidação. Isso também vale para diamantes. É oportuno lembrar que o que vai regular o mercado será geralmente o volume de oferta versus procura. Assim, podemos ter um diamante de qualidade ruim, ou seja, de baixo valor quando comparado à outra gema qualquer. No país infelizmente a escassez literária no que se refere aos adornos torna mais delicado ainda resgatar a história da bijuteria ou dos ornamentos corporais. Porém, a partir de acervos de museus, quadros, desfiles, livros históricos e de arte, revistas e filmes se encontram evidências que possibilitam alguns novos entendimentos para esses atavios.

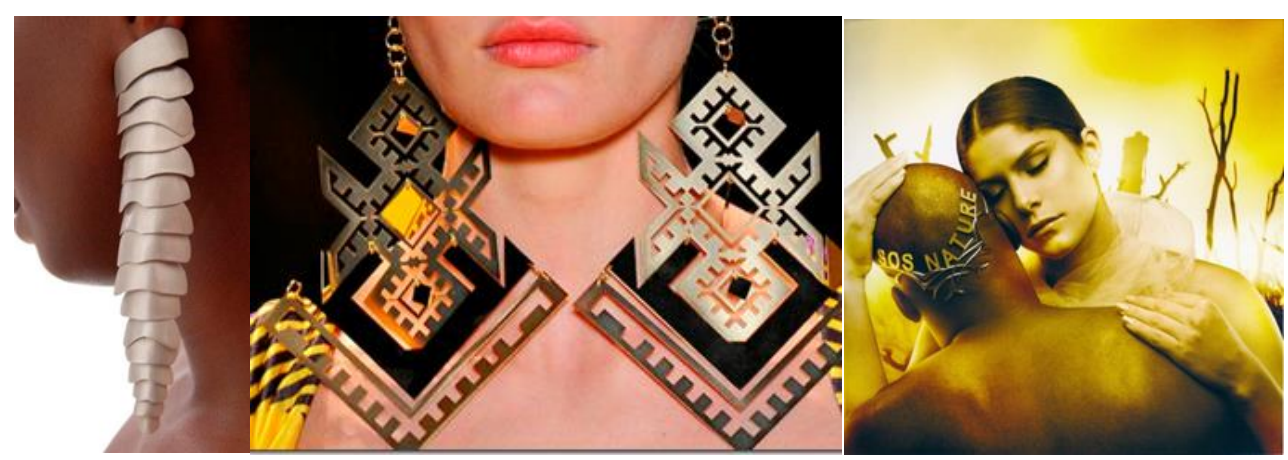

Figura 15 - Joia, brinco cerrado, Cerrado Mix. Fonte: cerradomix.maiscomunidade.com. Figura 16 - Maxibrinco Balada, Penolope Acessórios. Fonte: penelopeacessorios.com.br. Figura 17 - Ornato de cabeça. Lena Garrido, Anglo Gold Ashant. Fonte: www.flickr.com.

Do Brasil Colônia até início do século XX, joias, bijuterias e ornamentos corporais estiveram referenciados segundo os padrões da Europa (principalmente Portugal, França, Inglaterra e Itália). Em Rocha (2014), o joalheiro Salvador Francisco Neto afirma que a diferenciação concentrava-se na valoração dos materiais. Salienta ainda que um acervo incalculável perdeu-se com esse pensar. Muitas peças foram destruídas por causa do metal sem qualquer tipo de questionamento em relação ao valor das técnicas primorosas empregadas em sua construção. Já as bijuterias estiveram por 
um bom tempo, relacionadas ao baquelite (plástico) e ao vidro. Com materiais baratos, eram voltadas para o popular com produção em série e acabamento nem sempre esmerado, sob o lastro do descartável.

No tocante a arte plumária e afrobrasileira um grande acervo foi para terras estrangeiras sem uma real preocupação com preservação do patrimônio cultural e da tradição. Como foi dito ornamentos corporais eram relacionados aos povos originários, às técnicas mais rudimentares e ao regional. Algo sem um valor bem definido. Assim o destaque inicial vai para a beleza das penas, a diversidade de tramas de fibras naturais, as pencas de balangandãs, as correntes finamente forjadas, os frutos exóticos, as sementes e os braceletes, constituindo uma combinação de materiais, desenhos e cores exuberantes de forma singular. Hoje, ornamentos corporais estão referendados como tendências inovadoras e não apenas relacionados ao primitivo nos tempos digitalizados.

Do mesmo jeito para expressar-se um entendimento mais atual sobre a aproximação de fronteiras entre joia, bijuteria e adornos, é oportuno considerar que projetar e criar vai além do estético e do funcional, ou seja, vai além do produto em si seja ele material ou imaterial, conforme observa Held (2010, p. 22-34). O autor menciona, por exemplo, alternativas envolvendo inovação dentro de um perfil agregador entre cultura produtiva e o cultura mercadológica. E uma forma de desenvolver um olhar mais aprimorado, capaz de estabelecer as diferenças entre esses adornos com natural agilidade, seria voltar a atenção para alguns dos detalhes a seguir:

- Avanços tecnológicos (como solda, corte e lapidação a laser, softwares 3D e Photoshop, fotografia digital, biônica, nanotecnologia, aprimoramento dos banhos de metais coloridos);

- Disponibilidades dos recursos materiais (incluindo gemas naturais e sintéticas, vidros especiais, super-resinas e plásticos, tecidos inteligentes, porcelanatos, metais como nióbio, titânio e alumínio);

- Capacidade inventiva associada ao intercâmbio cultural, que considerando situações como eventos sazonais ou cotidianos na evolução do sistema moda;

- Sistema produtivo (produção artística, industrial, artesanal, regional ou globalizada) voltado para questões como durabilidade e descarte, no entendimento do que é design no país; 
- Prestação de serviços, comercialização e hábitos de consumo, relação entre custo benefício e preservação do meio ambiente.

Todos esses eventos corroboram na conceituação e diferenciação das peças. Assim, é possível considerar que existem bijuterias e ornamentos corporais tão requintados e com qualidade excepcional que chegam a ser mais caros do que muitas joias. O mesmo vale para ornamentos corporais.

Para estabelecer as diferenças temos que considerar o conjunto da obra. Portanto, no que se refere a técnicas e materiais empregados é fato que os limites são próximos e complexos em sua demarcação. Isso pressupõe o uso de diversos referenciais. Como vimos na atualidade os objetos em questão podem ser feitos com todo o tipo de material, em maior ou menor escala ou até com exclusividade visto que o homem contemporâneo deu asas maiores para seu desejo de se diferenciar. Isso significa compreender a cultura mundo onde o contemporâneo aferi questões ligadas à desterritorialização, ao hipertecnológico, ao hiperconsumo individualista e infantilizado, à globalização via conexão online em tempo integral, ao universo das marcas que hibridam-se com a arte, às rupturas com verdades absolutas.

O questionamento é uma constante em que tudo é possível, todas as possibilidades são e não são válidas e as contradições são parte do cotidiano. Por fim essa desordem generalizada acaba por estimular o homem na busca pelo religamento, pela reconciliação entre o passado e o presente, a técnica e a natureza, a tradição e a liberdade. Nesse momento da história não há regras unificadas e cada caso é considerado com postura flexível na busca por condições de vida melhores e mais seguras. É preciso investir cada vez mais no capital humano, na educação, na socialização e em pesquisa. A economia deve estar voltada, segundo Lipovetsky (2008) na direção do conhecimento sem protecionismo de qualquer tipo para tornar o homem capaz de se reinventar.

Com essa proposição, uma joia não precisa conter ouro para ser joia ou um ornamento pode ter um metal nobre e não ser considerado joia. Essas observações, apesar de serem intrigantes num primeiro momento, propiciam um olhar amadurecido e mais aberto para novas conclusões. É plausível considerar que as fronteiras entre joias, bijuterias e ornamentos corporais no contemporâneo não podem ficar restritas aos materiais empregados, a um comércio mais agressivo ou a um marketing mais atuante. 
Talvez esses limites que em alguns casos chegam a ser sutis possam ser estabelecidos por meio de um aprendizado identificado com a nossa digital cultural. $\mathrm{O}$ design pode possibilitar esse avanço por meio de uma gestão adequada.

É pertinente aguçar a percepção para o autóctone, considerar, buscar e descobrir valores conectados ao contexto do Brasil, que por ser único possibilita um emprego diversificado de materiais e técnicas dentro de alternativas bem peculiares. Um reconhecimento mais eficaz dessas divisas deve levar em conta aspectos voltados para o arranjo estético constituído, a genialidade do autor, a originalidade do desenho e do projeto e a maestria em sua execução. Afinal, uma combinação equilibrada de fatores leva à construção de um perfil próprio e inconfundível para cada um desses ornatos. É inegável que no mundo contemporâneo a busca por materiais inusitados continua uma constante.

Talvez a necessidade de diferenciar-se faça parte da natureza humana como está destacado nas Figuras 18, 19 e 20. Ferramentas primitivas usadas na produção de adornos continuam presentes na atualidade principalmente nas técnicas de lapidação, cravação e ourivesaria. No início do século XX as diferenças entre joia e bijuteria no Brasil eram enormes, pautadas nas influências europeias e apenas no valor dos materiais. O plástico, o acrílico, o vidro, os banhos de metais e a baquelite tinham relação íntima com a bijuteria do mesmo modo que a joia tinha com o ouro, a prata e as gemas e, de outro lado, os adornos com plumagens, sementes e fibras, entre outros.

Joias eram valoradas em função da nobreza de seus metais e gemas sendo muitas vezes tratadas apenas como investimento financeiro; a bijuteria ganhou mercado inicialmente por seu valor estético. Contudo, com os anos, a bijuteria passou a se destacar também por seu caráter inovador. Nesse sentido o design teve e tem papel importante. O adorno corporal evoluiu da mesma forma que a joia e a bijuteria, desvinculando-se sob um certo aspecto da antiga conotação depreciativa e estabelecendo um caráter inovador com critérios de avaliação semelhantes ao das artes. Se considerarmos apenas a abordagem etimológica as diferenças estabelecidas são simplistas. 

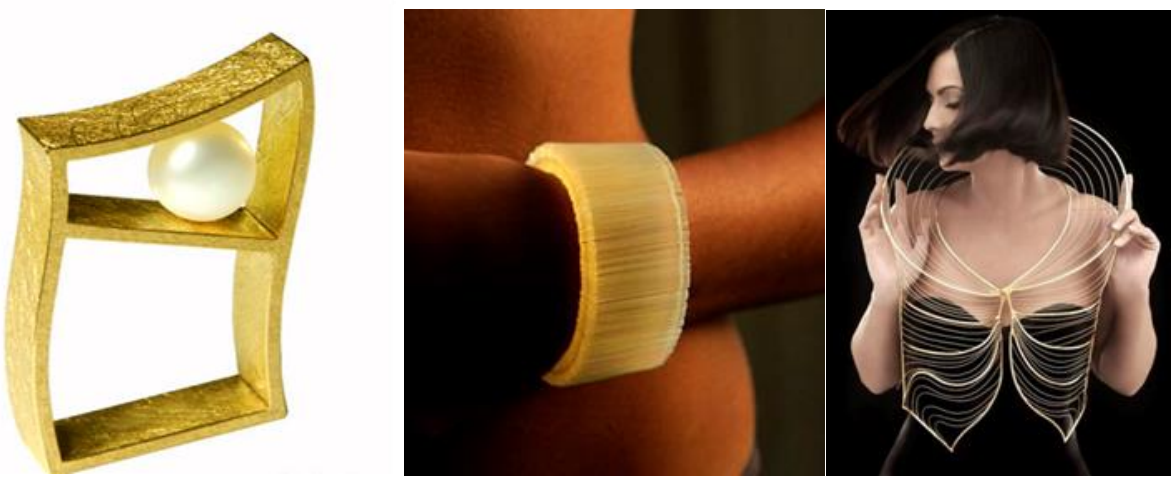

Figura 18 - Anel Ciça, Alfredo Grosso. Fonte: www.40forewer.com.br.

Figura 19 - Pulseira de acrílico, Mana Bernardes. Fonte: www.abcdesign.com.br.

Figura 20 - Ornamento corporal, Anglo Gold Ashant. Fonte: www.midiorama.com.br.

\section{Considerações finais}

A conceituação pode ser estabelecida pelo conjunto da obra. Adicionar valor pela depreciação de um atavio ou de outro não é a melhor alternativa. O mesmo vale para qualquer tentativa de imputar maior ou menor importância social para um ou outro artefato. Joia, bijuteria e ornamentos são adornos com características que não podem ser niveladas ou comparadas, todas têm seu valor próprio. Num outro ângulo, ainda que não se tenha um registro acadêmico formalizado ou uma normatização mínima compatível com nossa produção, esses adereços têm seu significado histórico garantido dentro do contexto da moda por meio de imagens em livros de história e arte, revistas, cartórios de inventários e museus.

No contemporâneo, buscar uma visão epistemológica favorece a compreensão mais profunda de nosso tempo e do comportamento hedonista que alimenta o consumo desenfreado de produtos e serviços. Podemos observar que o design tem laços estreitos com o politico-econômico e, dialoga no âmbito da prospecção, criação, projeção e gerenciamento, através da inter e transdisciplinaridade. Desse modo há a formatação de um movimento sinergético contínuo, que talvez consiga redirecionar esse frenesi social. Pensamentos que indicam que projetar e criar abrangem aspectos que extrapolam o estético e o funcional, ou seja, vão além do produto em si seja ele material ou imaterial. A inovação dentro de um perfil que reúne cultura produtiva e cultura mercadológica de forma mais eficiente é um paradigma a ser explorado.

A cultura do Brasil está em contínua construção. Experiências de outros lugares podem ser um parâmetro inicial de algumas possibilidades para o estabelecimento de uma estratégia. Mas a busca por soluções exige ideias pertinentes às necessidades 
próprias de cada uma de nossas regiões, marcadas por diferenças culturais significativas. Vale repetir a máxima de que uma educação de qualidade conduz à autonomia e assim pode-se alcançar uma compreensão mais realista do valor de nosso patrimônio cultural. Nesse sentido o design pode mediar com a eficiência necessária a conjunção das informações. Esse gerenciar peculiar e complexo possibilita a construção de um ambiente propício para o desenvolvimento de estudos que conduzam a soluções favoráveis às urgências mencionadas. O resgate da história de nossa joalheria, e consequentemente de técnicas quase desaparecidas e da obra de tantos mestres, deve ser meta desse processo. Criatividade e ousadia podem significar explorar as mais variadas ideias e materiais com estratégia, disciplina e determinação num cenário profissional, livre de medos e preconceitos. Essa pode ser nossa melhor opção.

\section{Artigo recebido em Outubro de 2015. Aprovado em Dezembro de 2015 DOI:http://dx.doi.org/105965/1982615×09012015140}

\section{Referências}

ALLÉRÈS, D. Luxo...........Estratégias, Marketing. Rio de Janeiro: FGV Editora, 2006, p. 264.

BARROSO E. Artesanato e design e O que é artesanato. Módulos I e II. Termo de referência Economia Criativa. In: Fórum Brasileiro de Economia Solidária. Brasília, 2013.

BISOGNIN, E. L. et al. Adornos nas civilizações pré-históricas sob a ótica da ourivesaria. Revista Competência, Revista da Educação Superior do Senac - RS, Porto Alegre, v.5, n. 1, p. 57-70, 2012.

GOLA E. A Joia, História e Design. São Paulo: Editora Senac, 2008, p. 24-40. 
GIORDANI, M. C. História da Antiguidade Oriental. Petrópolis: Editora Vozes, 1983.

HELD, M. S. B. A arte, o design, a moda - o processo de criação e o consumo na pósmodernidade. Revista: Poéticas Visuais. Unesp- Bauru, Bauru, v. 1, n.1, p. 22-34. 2010. HESKETT, J. Design. São Paulo: Ática, 2008, p. 13.

LODY, R. Joia de Axé, a joalheria afro - brasileira. Rio de Janeiro: Editora Bertrand Brasil Ltda, 2011.

LIPOVETSKY, G. A cultura mundo, uma resposta a uma sociedade desorientada. Cia das Letras: São Paulo, 2008.

MEDINA G. Módulos artesanais aplicados ao mobiliário, uma experiência em design social. Novo Hamburgo, 2009, p. 5.

MJSA, Manufacturing Jeweler and Suppliers Association/ Sintra. Pequena história da Indústria de Bijuteria Americana. Providence, Rhode Island. Tradução Crebi (The Global Jewelry Information Website)/ Sintrajoias (Sindicato dos trabalhados da Indústria Joalheira de São Paulo).2014.

NIEMEYER, L. Design Contemporâneo no Brasil. In: MOURA, Mônica (Org.) et al. Design Brasileiro Contemporâneo: reflexões. São Paulo: Estação das Letras, 2014, p. $35-46,69$.

RIBEIRO D. ; RIBEIRO B. 2010. "Arte plumária dos Índios Kaapor”. In Educação em Linha: Índios, os primeiros brasileiros. Secretária de Estado do Rio de Janeiro, 2010, v.13, n.1, p.51.

ROCHA, S. C. S. O Brasil da joia design e arte. São Paulo: Gráfica Editora Coppola, 2014, p.39-50, 120.

SEBRAE, Serviço Brasileiro de apoio às Micro e Pequenas Empresas. "A atuação do sistema SEBRAE no artesanato". Organização texto Durcelice Cândida Mascêne e 


\section{ModaPalavra E-periódico}

Maurício Tedeschi. Termo de referência economia criativa e inovação. São Paulo: SEBRAE, 2010. 